\title{
VITA | UBS CAXIMBA
}

\section{VITA | UNIDAD BÁSICA DE SALUD CAXIMBA}

\section{VITA | CAXIMBA'S BASIC HEALTH UNIT}

\section{ESTEVES, INGRID}

Estudante de graduação, Escola de Arquitetura e Urbanismo, Universidade Federal Fluminense, ingridmachadoesteves@gmail.com

\section{RANGEL, THAYNÁ}

Estudante de graduação, Escola de Arquitetura e Urbanismo, Universidade Federal Fluminense, thayna.bat.rangel@gmail.com

\section{FONTENELLE, MARILIA}

Arquitetura e Urbanista, Doutora, Professora Adjunta do Departamento de Arquitetura da Universidade Federal Fluminense, mariliafontenelle@id.uff.br

\section{INTRODUÇÃO}

Cuidar da saúde e tratar enfermidades é inerente a todo ser humano e, principalmente em unidades de saúde, dependem de conexões entre pessoas: agentes de saúde e pacientes. Apesar disso, a sensação de isolamento e retirada do convívio social é, frequentemente, latente no processo de recuperação e tratamento de doenças. Esta associação pode gerar desconforto psicológico para encarar com naturalidade o ambiente hospitalar, seja para tratamento ou prevenção. O projeto da Unidade Básica de saúde - Caximba, evoca o conceito de vitalidade como estruturador de uma percepção que estimule a inclusão na vida social e reconecte o paciente ao meio externo.

O partido adotado, através da implantação do edifício em uma praça, de forma fragmentada e linear, busca proporcionar a dissolução de barreiras entre interior e exterior através de caminhos que transpassam o terreno da UBS com ambientes de convívio, lazer e atividade, adicionando dinamismo e qualidade à experiência urbana dos moradores. Da mesma forma, em suas dependências internas, circulações amplas e iluminação zenital foram utilizadas para desconstruir a sensação de isolamento e enclausuramento, e potencializar a sensação de vigor e energia.

\section{DESENVOLVIMENTO DA PROPOSTA}

\subsection{CONTEXTO SOCIOTERRITORIAL}

Localizado na Zona Bioclimática 1, no extremo sul de Curitiba-PR, o bairro Caximba - Regional Tatuquara, Latitude: -25,4244 e Longitude: -49,2654 - possui uma expressiva demanda de regularização fundiária e caracteriza-se pela informalidade do parcelamento e ocupação, resultando na dificuldade de acesso da população local aos bens e serviços sociais como um todo.

Segundo diagnóstico ${ }^{1}$ realizado no ano de 2017 pelo Ministério Público PR, estima-se que a população residente na região tenha sofrido aumento de 356\% no período entre 2010 e 2017. Ainda segundo o mesmo diagnóstico, o bairro possui uma Unidade de saúde da Família projetada para atender cerca de 3.000 pessoas, mas que esta, no ano de 2017, já contava com 8.815 cadastros definitivos. Este quadro demonstra a insuficiência de estrutura para atendimento da população, tendo em vista os parâmetros estabelecidos na portaria 2.488/2011 do Ministério da Saúde, que dispõe que cada equipe de saúde da família deve ser responsável por, no máximo, 4.000 pessoas, sendo a média recomendada de 3.000 pessoas, de acordo com o grau de vulnerabilidade das famílias daquele território - quanto maior o grau de vulnerabilidade, menor deverá ser a quantidade de pessoas por equipe. 
Neste sentido, considerando a demanda excedente e mediante o conjunto de condições de vulnerabilidade socioeconômica e riscos epidemiológicos da região, o programa, indicado pelo Ministério da Saúde como Porte II (portaria N².226/2009), é destinado a abrigar 3 equipes de saúde da família, além de considerar diretrizes municipais tais quais espaço para auriculoterapia e acupuntura.

\subsection{CONTEXTO BIOCLIMÁTICO}

A cidade se caracteriza por um clima temperado úmido (Temperatura média mínima anual $\mid 8,5^{\circ} \mathrm{C}$ Junho e Temperatura média máxima anual $\mid 27^{\circ} \mathrm{C}$ - Janeiro) com elevada amplitude térmica, que apresenta variações entre $8^{\circ}$ e $11^{\circ} \mathrm{C}$, e alta umidade relativa do ar (variando entre 82 e $89 \%$ ). A Carta Solar aponta o solstício de verão com 13h e o solstício de inverno com 10 horas de insolação aproximadamente, e a rosa dos ventos aponta predominância Leste (Figura 1).

Figura 1: Rosa dos ventos e Carta Solar | Cidade Curitiba
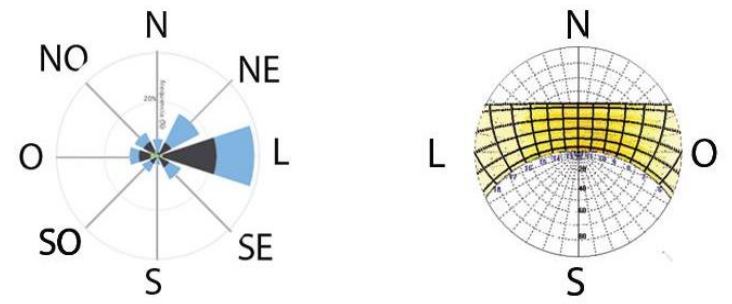

Fonte: Plataforma Projetee (MMA, 2019)

O gráfico de condições de conforto (MMA, 2019) indica que apenas 15\% dos dias do ano apresentam conforto térmico. Assim, existe a necessidade da aplicação de estratégias que revertam essa situação de $77 \%$ dos dias com desconforto por frio e $8 \%$ dias do ano com desconforto por calor através das estratégias bioclimáticas de inércia térmica para aquecimento ( $57 \%$ ano), aquecimento solar passivo (24\% ano) e ventilação natural (10\% ano).

Ao cruzar os dados da rosa dos ventos com as características topográficas da área (Figura 2), verificase que a incidência dos ventos dominantes - leste -, bem como os de norte e oeste são bloqueadas por cadeias montanhosas no entorno. Desta forma, apenas os ventos Nordeste e Noroeste efetivamente incidem no terreno.

Figura 2: Análise de ventos incidentes no terreno
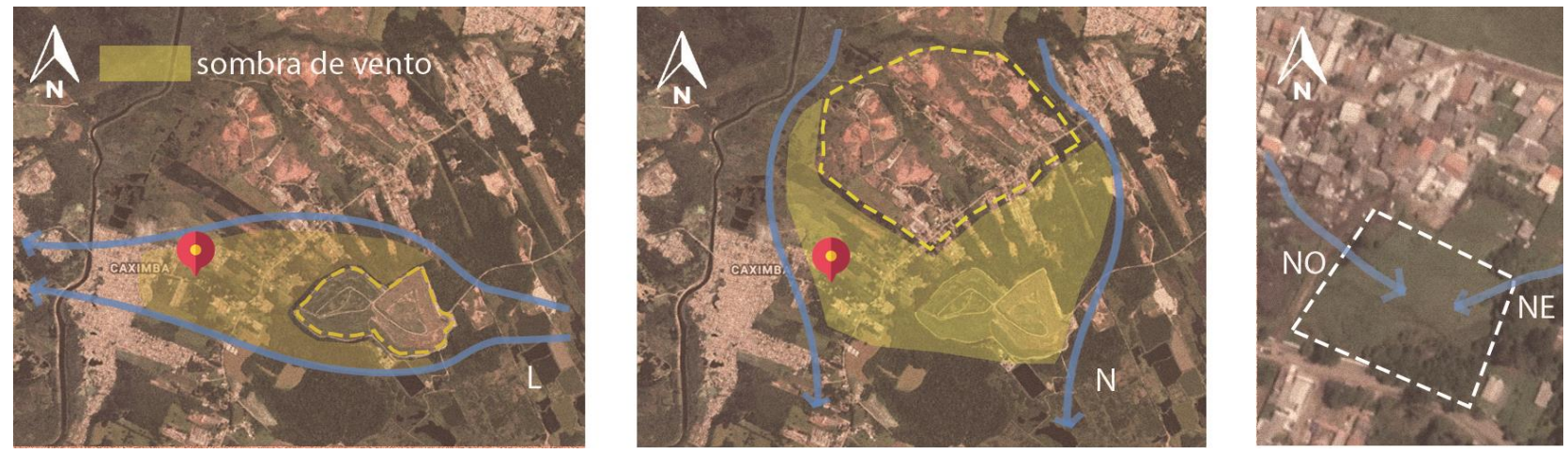

Fonte: Produção das autoras a partir de imagens aéreas do Google Earth

\subsection{PARTIDO ARQUITETÔNICO}

Por conta do grande adensamento da região, da informalidade de seus loteamentos e da carência de áreas de lazer, o projeto buscou corresponder a essas demandas através da criação de uma praça e de vias circundantes, a fim de possibilitar uma melhor mobilidade urbana e propor uma relação mais harmoniosa e pulsante entre a UBS e os edifícios de entorno. A caminhabilidade e o uso de modais ativos foram incentivados através da criação de eixos amplos de circulação e de uma ciclofaixa que conduz ao interior do terreno. Um grande eixo atravessa o lote, conectando uma das principais ruas do bairro às vias locais, convidando o 
pedestre a adentrar a praça e realizar um caminho mais interessante no dia a dia. Esta medida leva movimento ao lugar, reforça o conceito proposto e estimula os moradores a movimentar-se e adquirir hábitos saudáveis (Figura 3).

Em resposta às estratégias de aquecimento solar passivo e inércia térmica para aquecimento indicadas para a cidade, o edifício foi implantado com as maiores fachadas para as implantações norte-sul, para o máximo aproveitamento da radiação solar e por apresentar uma maior eficiência energética (MASCARÓ,1991). A planta linear objetiva potencializar a captação dos ventos incidentes vindos de Nordeste e de Noroeste, respondendo à estratégia de ventilação natural, também indicada, principalmente nas áreas de atendimento (Figura 3).

Figura 3: Projeto implantado, seu entorno e indicação de intervenções urbanas

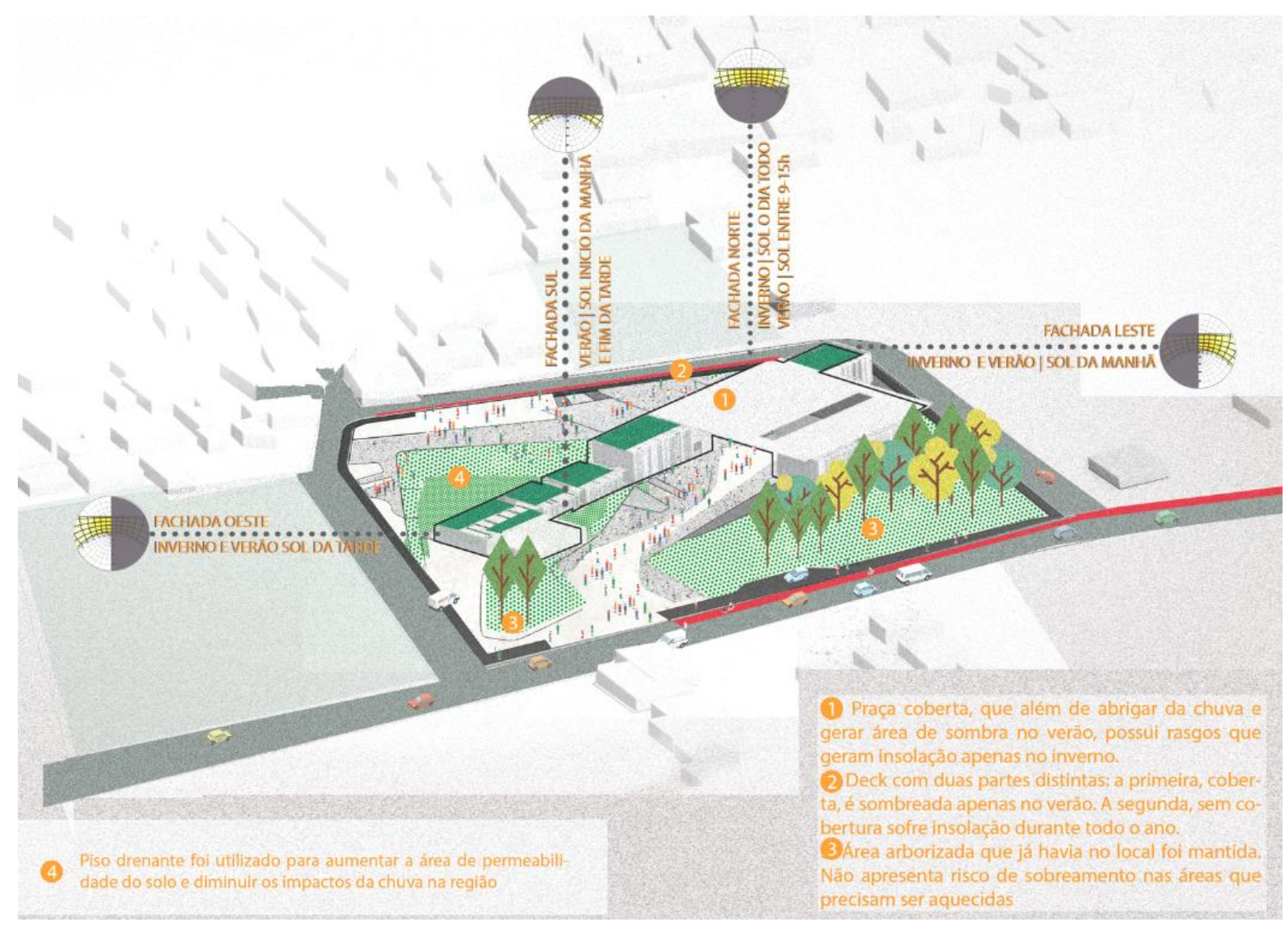

Fonte: Produção das autoras

A morfologia urbana foi considerada na implantação, de maneira que a fragmentação (Figura 4) fosse utilizada para que o edifício não destoasse dos gabaritos e das dimensões de testada comuns às construções do entorno, e considerasse a necessidade de cuidados quanto à funcionalidade, ao risco de contaminação e a NBR 9050 de acessibilidade universal.

Corredores envidraçados e com pé direito mais baixo foram utilizados para acentuar esta fragmentação, sem perder a conexão interna entre os blocos. Já nos locais de alta concentração de pessoas foi utilizado pé direito duplo associado a aberturas zenitais, a fim de minimizar a sensação de isolamento e enclausuramento. As aberturas foram posicionadas de maneira a captar os ventos incidentes respondendo a estratégias de ventilação natural, também indicada. Com o intuito de explorar a ventilação em períodos sem incidência direta dos ventos no terreno, foi aplicado o sistema de termosifão, por meio de aberturas zenitais que exercem a sucção do ar dos ambientes.

$\mathrm{Na}$ fachada Norte, onde há maior insolação - alto potencial de aquecimento - e maior captação dos 
ventos, foram posicionadas as áreas de alta permanência, com pé direito mais baixo, para potencializar o aproveitamento do calor. Como a cidade apresenta altas temperaturas durante o verão, proteções solares foram aplicadas para evitar superaquecimento nessa época do ano. As circulações - de baixa permanência - foram posicionadas na fachada Sul, onde foi proposto aberturas zenitais, que geram uma sensação de amplitude (Figura 4).

Figura 4: Planta Baixa e volumetria da proposta

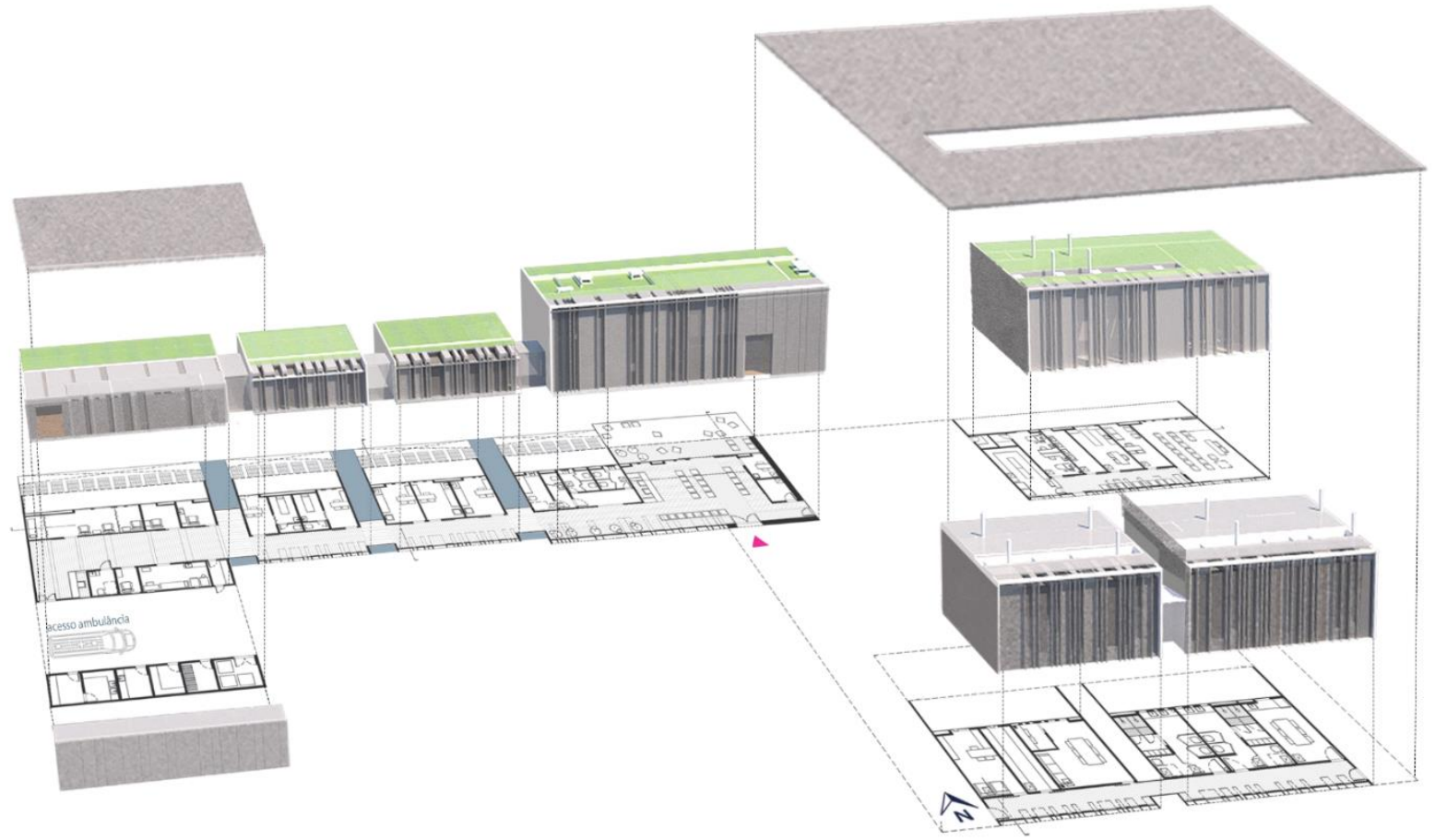

Fonte: Produção das autoras

Por conta do grande risco de propagação de doenças através do ar, foram instalados dutos (Figura 5) que conduzem o ar das áreas de atendimento para fora do edifício. Estes elementos fazem a separação entre ar contaminado e o das áreas de circulação e minimizam os riscos de contágio entre os pacientes. A renovação do ar nas áreas de circulação, por sua vez, é feita por exaustão através de aberturas nas superfícies transparentes.

Figura 5: Corte Longitudinal - Sistema de exaustão através de dutos

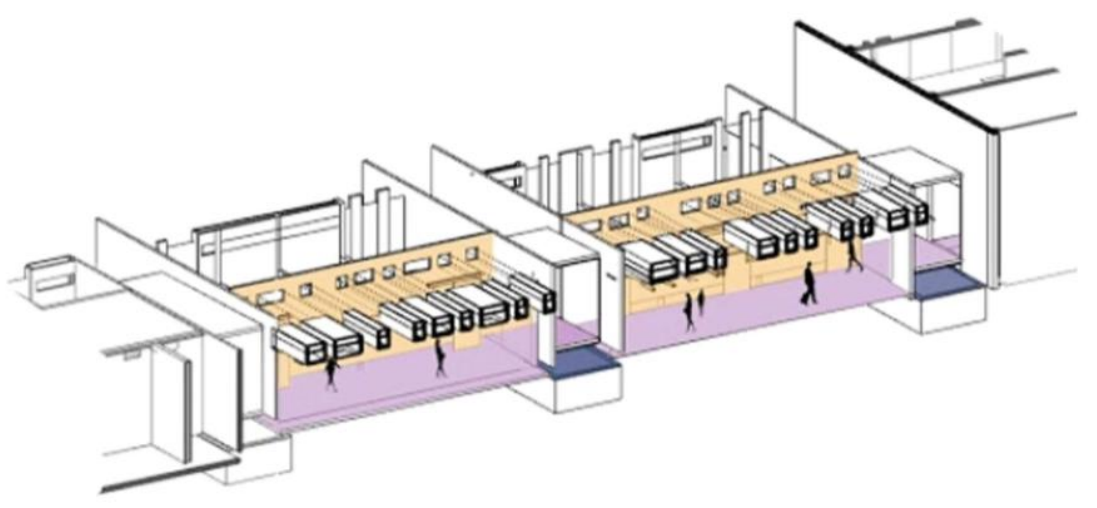

Fonte: Produção das autoras

Placas fotovoltaicas foram posicionadas de acordo com os parâmetros técnicos necessários para seu pleno funcionamento: voltadas para Norte, com angulação de $35^{\circ}$, equivalente a latitude de $25^{\circ}$ (Curitiba) +

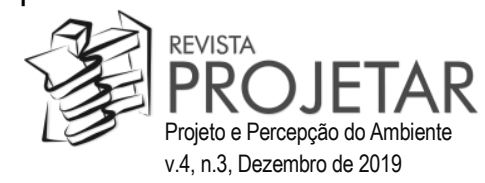


$10^{\circ}$. O sistema foi aplicado no embasamento do edifício para que a radiação incidente na cobertura fosse utilizada na inércia térmica para aquecimento, o que seria impossibilitado caso as placas fossem instaladas nesta. Associada ao fosso, e com distância suficiente para não sofrer sombreamento, a área de instalação assegura privacidade das áreas de atendimento, pois cria um recuo até as superfícies transparentes, sem impedir a integração visual interna com o exterior (Figura 6).

Figura 6: Corte Transversal - Demonstração de funcionamento dos sistemas

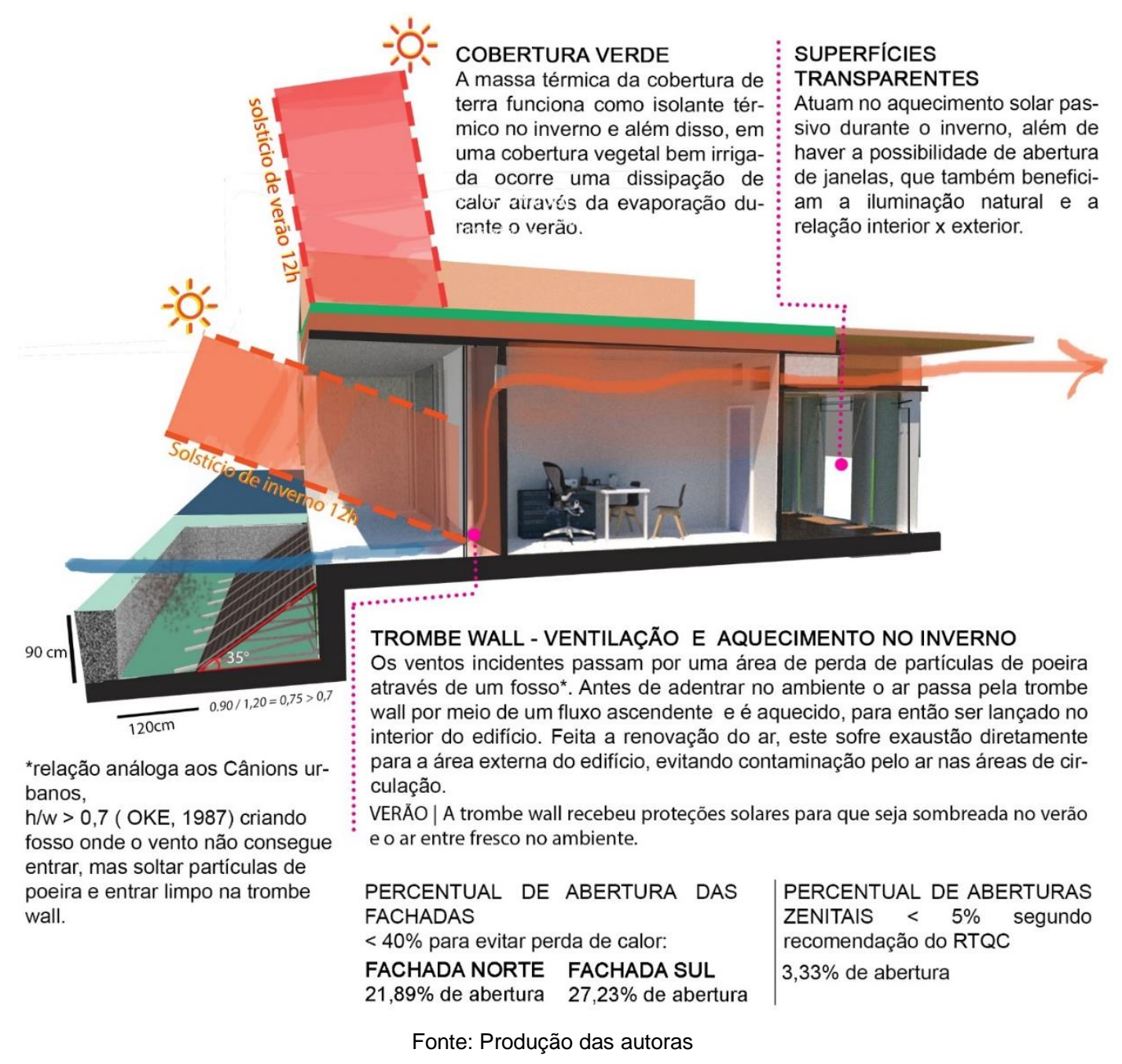

O dinamismo da edificação se dá através do uso de ritmo nas fachadas, forro, aberturas zenitais, todos com diferentes dimensões- gerando uma gama de sensações - alto, baixo, luz, sombra, dentro, fora. A amplitude também foi explorada ao inserir uma visada para o espelho d'água nos corredores de ligação entre os blocos - completamente envidraçados.

Destaca-se o uso de peças pré-fabricadas modulares, com variações da dimensão mínima de $25 \mathrm{~cm}$. Este padrão acompanha as esquadrias, proteções solares, sistema estrutural, dutos de ventilação - que também conformam o forro, proporcionando ritmo e dinamismo no teto - e auxiliam na configuração dos espaços. Este tipo de construção foi adotado por ser mais limpa, racional e por apresentar possibilidade de flexibilidade para diferentes usos e tratamentos.

\section{CONSIDERAÇÕES FINAIS}

O projeto buscou, na humanização e no conforto dos espaços, explorar a premissa de que a arquitetura deve ser feita para as pessoas. Reforçou também a necessidade de dissolução entre as barreiras existentes no que diz respeito ao isolamento e ao convívio social, já que ficar doente faz parte do processo natural humano e não há a necessidade de ficar afastado da vida quando se está doente. 
Um ponto que vale ser ressaltado é o da fundamental aplicação de estratégias bioclimáticas indicadas para o contexto local do projeto, principalmente por se tratar de um edifício público, onde a redução do consumo de energia e a extensa vida útil da edificação são essenciais.

\section{REFERÊNCIAS}

MASCARÓ, L. Energia na Edificação - estratégias para minimizar seu consumo. São Paulo: Editora Projeto, 1991.

OKE, T.R. Street design and urban canopy layer climate. Energy and Buildings. Department of Geography, The University of British Columbia. Vancouver - Canadá, 1987. Disponível em:

https://www.sciencedirect.com/science/article/pii/0378778888900266. Acesso em Outubro / 2019.

MMA - Ministério do Meio Ambiente. Plataforma PROJETEEE: Projetando Edificações Energeticamente Eficientes. Disponível em: http://projeteee.mma.gov.br/. Acesso em: Outubro / 2019.

${ }^{1}$ Diagnóstico Socioterritorial Caximba | CAEx/ NATE- Núcleo de Apoio Técnico Especializado. Resolução PGFJ. № $4467 / 2013$

NOTA DO EDITOR $\left(^{\star}\right.$ ) O conteúdo do artigo e as imagens nele publicadas são de responsabilidade do(s) autor(es). 